\title{
Synaptic Plasticity Defect Following Visual Deprivation in Alzheimer's Disease Model Transgenic Mice
}

\author{
Christopher M. William, ${ }^{1,2}$ Mark L. Andermann, ${ }^{3}$ Glenn J. Goldey, ${ }^{3}$ Demetris K. Roumis, ${ }^{3}$ R. Clay Reid, ${ }^{3}$ Carla J. Shatz, ${ }^{4}$ \\ Mark W. Albers, ${ }^{2}$ Matthew P. Frosch, ${ }^{1,2}$ and Bradley T. Hyman ${ }^{2}$ \\ ${ }^{1}$ Neuropathology Service, ${ }^{2}$ MassGeneral Institute for Neurodegenerative Disease, Neurology, Massachusetts General Hospital, Charlestown, Massachusetts \\ 02129, ${ }^{3}$ Department of Neurobiology, Harvard Medical School, Boston, Massachusetts 02115, and ${ }^{4}$ Bio-X, Stanford University, Stanford, California 94305
}

Amyloid- $\beta(\mathrm{A} \beta)$-induced changes in synaptic function in experimental models of Alzheimer's disease (AD) suggest that $\mathrm{A} \beta$ generation and accumulation may affect fundamental mechanisms of synaptic plasticity. To test this hypothesis, we examined the effect of APP overexpression on a well characterized, in vivo, developmental model of systems-level plasticity, ocular dominance plasticity. Following monocular visual deprivation during the critical period, mice that express mutant alleles of amyloid precursor protein (APPswe) and Presenilin1 (PS1dE9), as well as mice that express APPswe alone, lack ocular dominance plasticity in visual cortex. Defects in the spatial extent and magnitude of the plastic response are evident using two complementary approaches, Arc induction and optical imaging of intrinsic signals in awake mice. This defect in a classic paradigm of systems level synaptic plasticity shows that $\mathrm{A} \beta$ overexpression, even early in postnatal life, can perturb plasticity in cerebral cortex, and supports the idea that decreased synaptic plasticity due to elevated A $\beta$ exposure contributes to cognitive impairment in AD.

\section{Introduction}

Amyloid- $\beta(\mathrm{A} \beta)$ production and accumulation have been implicated in the pathogenesis of Alzheimer's disease (Tanzi et al., 1987; Goate et al., 1991; Prasher et al., 1998; Nilsberth et al., 2001; Bentahir et al., 2006; Kumar-Singh et al., 2006; Rovelet-Lecrux et al., 2006). Exposure to soluble and fibrillar forms of $A \beta$ is associated with synapse loss (Hsia et al., 1999; Walsh et al., 2002; Spires et al., 2005; Shankar et al., 2007), which may be mediated by a direct effect of $A \beta$ on synaptic function: acute, exogenous application of oligomeric human $\mathrm{A} \beta$ to organotypic hippocampal cultures blocks LTP induction (Lambert et al., 1998; Chen et al., 2002; Walsh et al., 2002), and lowers the threshold for induction of LTD (Kim et al., 2001; Shankar et al., 2008). Moreover, this synaptic activity may relate to a normal function of $A \beta$ in synaptic physiology (Abramov et al., 2009).

These considerations suggest that elevation of $A \beta$ levels in humans could directly perturb synaptic function independent of the aggregation of protein in amyloid plaques. Here we examine this possibility in the developing mouse visual cortex using a well characterized paradigm of neural system plasticity, ocular dom-

Received Oct. 24, 2011; revised April 11, 2012; accepted April 23, 2012.

Author contributions: C.M.W., M.L.A., R.C.R., C.J.S., M.W.A.,M.P.F., and B.T.H. designed research;C.M.W., M.L.A., G.J.G., and D.K.R. performed research; C.M.W., M.L.A., G.J.G., and D.K.R. analyzed data; C.M.W., M.L.A., G.J.G., D.K.R., R.C.R., C.J.S., M.W.A., M.P.F., and B.T.H. wrote the paper.

This work was supported by NIH (Grants K08 NS069811 to C.M.W., R01 EY018742 to R.C.R., DP2 0 D006662 to M.W.A.), by the Dr. and Mrs. E.P. Richardson Jr. Fund for Neuropathology (C.M.W.), by a fellowship from the Ludcke Foundation and Pierce Charitable Trust (M.L.A.), and by the Mathers Charitable Foundation (C.J.S.). We thank Anthony Moffa for assistance with data collection and Sergey Yurgenson and Aleksandr Vagodny for technical contributions. We thank members of the Shatz, Hyman, and Reid laboratories for advice and discussion.

Correspondence should be addressed to Bradley T. Hyman, MassGeneral Institute for Neurodegenerative Disease, Neurology, Massachusetts General Hospital, 114 16th Street, Charlestown, MA 02129. E-mail: bhyman@partners.org.

DOI:10.1523/JNEUROSCI.5369-11.2012

Copyright $\odot 2012$ the authors $\quad 0270-6474 / 12 / 328004-08 \$ 15.00 / 0$ inance plasticity (ODP). ODP is triggered when one eye is closed or removed during a critical period of postnatal development (Gordon and Stryker, 1996; Tagawa et al., 2005; Smith et al., 2009; Tropea et al., 2009), thereby causing an increase in the responsiveness of neurons in primary visual cortex driven by visual stimulation of the open (or remaining) eye and a decrease in response to the closed eye. An expansion in the territory functionally connected to the open eye has also been observed (Tagawa et al., 2005). Although most robust during the critical period, similar phenomenon also occur in the adult (Sawtell et al., 2003; Tagawa et al., 2005; Fischer et al., 2007; Sato and Stryker, 2008). Here we report that APPswe-expressing transgenic mice demonstrate marked functional deficits in ODP that provide insight into the effect of $A \beta$ on synaptic function in the context of intact neural circuits responding to physiologically relevant changes in input.

\section{Materials and Methods}

Mice and eye surgery. All experiments were performed under national (United States National Institutes of Health) and institutional (Massachusetts General Hospital Subcommittee for Research Animal Care and the Institutional Animal Care and Use Committee at Harvard Medical School) guidelines. APP/PS1 mice (strain B6C3$\operatorname{Tg}$ (APPswe,PSEN1dE9)85Dbo/J; Jankowsky et al., 2001), and mice expressing PSEN1dE9 alone (strain B6.Cg Tg(PSEN1dE9)S9 Dbo/J; Savonenko et al., 2005), were obtained from the Jackson Laboratory. Mice expressing APPswe alone, strain Tg2576 (Hsiao et al., 1996), were also used. Unilateral lid suture was performed at P28 on transgenic and nontransgenic littermate mice; Arc induction was performed on P33, as described below. Monocular enucleation (ME) was performed on P32 mice to assay the Arc induction response in the absence of a prior period of unilateral deprivation or enucleation (Tagawa et al., 2005). ME was also performed at P22 to assess ocular dominance (OD) plasticity in 
visual cortex ipsilateral to the remaining eye $10 \mathrm{~d}$ later, with Arc induction performed on P33. Male and female mice were used in these experiments.

Arc mRNA induction. As described by Tagawa et al. (2005), at P32, just before Arc induction, ME was performed (unless animals had received $\mathrm{ME}$ at P22). The mouse cage was placed in a ventilated container in total darkness for $\sim 15 \mathrm{~h}$. The cage was then placed in bright, fluorescent lighting to permit a $30 \mathrm{~min}$ period of vision, following which mice were killed. Brains were removed and flash-frozen in M-1 mounting medium (Shandon, Thermo Scientific). Coronal cryosections $(8-10 \mu \mathrm{M})$ through visual cortex were collected on Superfrost slides (Fisher Scientific) for subsequent in situ hybridization analysis.

Arc in situ hybridization and analysis. As described by Schaeren-Wiemers and Gerfin-Moser (1993), Arc antisense probe template was derived by reverse transcriptase PCR from mouse brain mRNA (GenBank ID: NM018790, nt 262-1338) and cloned into pBluescript KS (Stratagene). Digoxigenin-labeled antisense riboprobe was transcribed in vitro using T3 RNA polymerase (Roche).

Measurements of the width of visual cortex containing neurons responding to stimulation of the ipsilateral eye, as assessed by induction of mRNA for the immediate early gene Arc, were made by drawing a segmented line parallel to the cortical surface through the Arc-positive domain of layers $2 / 3,4,5$ or 6 in primary visual cortex, using Image software (NIH). The measurements from at least six sections were used for each mouse to determine the width of the responsive domain. Statistical analysis was performed using Statview software (Version 5.0.1; SAS Institute). All measurements and analyses were performed blind to genotype.

Immunohistochemistry. Fresh frozen mouse brains were cryosectioned $(8-10 \mu \mathrm{m})$ and mounted onto slides for subsequent staining. For immunohistochemistry, sections were fixed for $10 \mathrm{~min}$ in $4 \%$ paraformaldehyde in PBS, washed, blocked with $10 \%$ goat serum in Tris-buffered saline (TBS), and then incubated overnight with anti-APP/A $\beta$ antibody 6E10 (1:1000; Covance). Slides were then stained with Cy3-conjugated anti-mouse IgG secondary antibody (1:200; Jackson ImmunoResearch) and coverslipped with DAPI-containing mounting medium (Vector Laboratories).

Biochemistry. Brain homogenates were prepared from a P28 APP/PS1 mouse and a nontransgenic litter mate. Brain homogenates were sequentially fractionated in TBS, $1 \%$ Triton X-100, and 2\% SDS. Immunoprecipitation with human $\mathrm{APP} / \mathrm{A} \beta$ antibody $6 \mathrm{E} 10$ was performed with each fraction. Immunostaining of resultant blots was performed with $6 \mathrm{E} 10$ and with an anti-N-terminal $\mathrm{A} \beta$ antibody, 82E1 (IBL International).

Cranial window and headpost implantation. In addition to Arc induction, we used intrinsic imaging as an independent means of assessing the integrity of plasticity responses in APP/PS1 and nontransgenic mice. Fifteen male and female mice underwent cranial window surgery in preparation for in vivo imaging of sensory responses in mouse primary visual cortex (8 APP/PS1 and 7 nontransgenic litter mates). For cranial window implant surgery, P22-P24 animals were anesthetized with isoflurane $\left(1.2-2 \%\right.$ in $\left.100 \% \mathrm{O}_{2}\right)$. Dexamethasone was administered on the day of the procedure $2-6 \mathrm{~h}$ before surgery $(3.2 \mathrm{mg} / \mathrm{kg}$, i.m.) and atropine was administered at surgery onset $(0.2 \mathrm{mg} / \mathrm{kg}$, i.p.). Using aseptic technique, a headpost was secured in place using cyanoacrylate, dental acrylic, and C\&B Metabond (Parkell), and a $5 \mathrm{~mm}$ craniotomy was made over the left visual cortex (center $\sim 2.5 \mathrm{~mm}$ lateral, $2.0 \mathrm{~mm}$ anterior to lambda) as described by Andermann et al. (2010). A $5 \mathrm{~mm}$ glass cranial window, consisting of an $8 \mathrm{~mm}$ coverslip cured to two $5 \mathrm{~mm}$ coverslips (Warner \#1; total thickness, $\sim 0.5 \mu \mathrm{m}$; thickness below skull, $\sim 200 \mu \mathrm{m}$ ) using index-matched adhesive (Norland \#71), was implanted. The window was secured in place using $\mathrm{N}$-butyl cyanoacrylate and C\&B Metabond, and the mice were allowed to recover for at least $4 \mathrm{~d}$. Imaging of ipsilateral and contralateral retinotopic acuity was then performed at age P28 (P27-P29; see below). In a subset of mice ( $N=6$ nontransgenic mice and 4 $A P P / P S 1$ mice), we also evaluated the effects of contralateral $4 \mathrm{~d}$ lid suture on binocular responses, beginning $2-4 \mathrm{~h}$ after recovery from suture removal.

Autofluorescence intrinsic imaging. Following recovery from headpost/ cranial window implant surgery, we mapped retinotopic organization of ipsilateral and contralateral responses, and strength of responses, in awake, head-restrained mice at age P28 (P27-P29; see Fig. 4). To map visual cortical responses, we used in vivo epifluorescence imaging (Husson et al., 2007; Tohmi et al., 2009) to measure changes in autofluorescence signal. Autofluorescence produced by blue excitation $(470 \mathrm{~nm}$ center, $40 \mathrm{~nm}$ band, Chroma Technology) was measured through a green/red emission filter (long-pass, $500 \mathrm{~nm}$ cutoff). Images were collected using a CCD camera (SensiCam, Cooke Corp.) at $2 \mathrm{~Hz}$ through a $5 \times$ air objective ( 0.14 numerical aperture, Mitituyo) using ImageJ acquisition software.

Visual stimulation. We presented visual stimuli using a $120 \mathrm{~Hz}$ LCD monitor (Samsung 2233RZ, 22 inches) that was calibrated with a spectrophotometer (Photo Research PR-650). The monitor was positioned directly in front of the mouse, perpendicular to its body axis, at a distance of $21 \mathrm{~cm}$. Stimuli were upwards-drifting square-wave gratings $\left(16^{\circ}\right.$ square patch, 0.03 cycles/degree, $2 \mathrm{~Hz}, 80 \%$ contrast) similar to those used by Hofer et al. (2009). Stimuli were placed at elevations of $\sim 20^{\circ}$ above the horizontal meridian. Stimuli were presented for $5 \mathrm{~s}$ each, with $15 \mathrm{~s}$ of blank monitor screen (mean luminance) between trials. Stimuli could be presented to the ipsilateral (left) or contralateral (right) eye separately, in subsequent runs, by carefully positioning an opaque plastic visor in front of the nonstimulated eye ( $<3 \mathrm{~mm}$ from the eye, just above the snout fur). Mice were not noticeably agitated by the placement of the visor. We first mapped ipsilateral retinotopic locations in primary visual cortex (V1) as follows. We presented stimuli at five horizontal retinotopic locations, each spaced $16^{\circ}$ apart (spanning the field from $\sim-40^{\circ}$ to $40^{\circ}$ surrounding the vertical meridian), in pseudorandom order (12 trials/ location). We then assessed which three contiguous stimulus locations were most effective at driving ipsilateral eye responses. The main stimulus protocol was then used, consisting of pseudorandom presentation of stimuli at these three retinotopic locations. We presented $4-5$ runs of stimulation per eye (60 trials per run total, 20 trials per stimulus location per run), with alternating stimulation of the ipsilateral or contralateral eye across runs to ensure that comparison of ipsilateral and contralateral responses over time was not influenced by nonstationary responses.

Optical imaging analysis. Visual responses consist of a small increase in the autofluorescence signal (corresponding to flavoprotein oxidization during increased metabolism; Tohmi et al., 2009) followed by a stronger negative signal (due to increased light absorption because of delayed increase in blood volume and deoxyhemoglobin concentration; Schuett et al., 2002). Thus, the response to a stimulus was computed as the percentage change in fluorescence $(\% d F / F)$ between the average of 6 frames recorded during the first $3 \mathrm{~s}$ following stimulus onset and the average of all 20 frames recorded from 9 to 19 s following stimulus onset. For presentation of imaging analyses, we have inverted the sign of the visual responses so that stronger responses correspond to more positive values. Imaging analyses were performed using Matlab software (MathWorks).

To test whether retinotopic responses to stimuli at different locations shifted in an orderly manner and were spatially localized in nontransgenic and APP/PS1 mice, we characterized the shifts in optical peak response location following stimulation at adjacent stimulus positions, as well as the width of optical response diameter, as follows. First, for each mouse, we obtained the one-dimensional response profiles along the line from peak response in $\mathrm{V} 1$ to peak response in lateromedial (LM) area, which has a binocular region adjacent and lateral to V1. This line was obtained manually by selecting the peak response in V1 and LM in response to contralateral eye stimulation at the rightmost stimulus location (see Fig. 4A,B). The one-dimensional (1-D) response profiles for each stimulus condition were then estimated as the maximal response in a region from -1000 to $1000 \mu \mathrm{m}$ perpendicular to the line between $\mathrm{V} 1$ and LM; this method minimizes the influence of vascular artifacts, which often had responses of the opposite sign to neuropil responses). The V1/LM border was defined as the midpoint between the peak responses in V1 and LM. All 1-D profiles were then low-pass filtered $(465 \mu \mathrm{m}$ cutoff). Peak V1 responses along the LM/V1 axis were then estimated for each stimulus position, in the region from 0 to $800 \mu \mathrm{m}$ from the V1/LM border. For estimation of response bandwidth, we calculated the bandwidth at half of peak response (FWHM), again using the response to the rightmost stimulus presented to the contralateral eye in P28 mice. 
We obtained a measure of response strength for both ipsilateral (ipsi) eye and contralateral (contra) eye stimulation (see Fig. 5) in the binocular region of $\mathrm{V} 1$ by averaging the 1-D response profiles for all three stimulus types presented in the main stimulus protocol, in the region in V1 from 100 to $350 \mu \mathrm{m}$ medial to the V1/LM border (see Fig. $5 A$ bottom, $B$ ). To obtain a measure of ocular dominance selectivity of this cortical region, i.e., selectivity for IPSI or CONTRA stimulation, we computed an ocular dominance selectivity index, ODI $=\left(R_{\text {contra }}-R_{\text {ipsi }}\right) /\left(R_{\text {contra }}+R_{\text {ipsi }}\right)$. ODI values of 1 and -1 correspond to responses to contra or ipsi eye stimulation only, while ODI values equal to 0 indicate a perfectly balanced response to stimulation of either eye. We chose this index because it is less sensitive to changes in overall response strength than $R_{\text {contra }} / R_{\text {ipsi }}$ (note that for nontransgenic mice, calculation of $R_{\text {contra }} / R_{\text {ipsi }}$ in our sample resulted in values of $\sim 2.5$ and $\sim 1$ before and after $4 \mathrm{~d}$ monocular deprivation (MD), respectively, which is consistent with results by Hofer et al., 2009).

For mice in which ODI indices could be directly compared in successive imaging sessions pre-MD (P27-P29) and post-MD (P31-P33), we ensured analysis of the identical cortical region in both sessions by aligning all images from the post-MD imaging session to the pre-MD imaging session using Matlab software (Mathworks). For all experiments, the duration of MD between imaging sessions was kept nearly constant $(96 \pm 2 \mathrm{~h})$.

To compare ODI indices from pre- and post-monocular deprivation (see Fig. $5 C$ ), we coregistered images obtained pre-MD and post-MD by applying the same vasculature-based affine transformation to all post-MD images using Matlab. This ensured estimates of responses from the identical location in cortex for pre-MD and post-MD sessions. All measurements and analyses were performed blind to genotype.

\section{Results}

Expression of $\mathrm{A} \boldsymbol{\beta}$ in critical period-age transgenic mice

APP expression in the mice studied here (APP/PS1 mice) has been detected as early as 4 months of age (Garcia-Alloza et al., 2006). However, the critical period for ODP is even earlier, from P19 to P34 (Gordon and Stryker, 1996; Tagawa et al., 2005), prompting us to assess whether detectable transgene and protein products are present at these ages in transgenic mice. Immunoprecipitation of sequentially extracted fractions from P28 transgenic and nontransgenic mouse brain homogenates with an antibody that recognizes human $\mathrm{APP}$ and $\mathrm{A} \beta$ (6E10; Covance), followed by immunoblotting with $6 \mathrm{E} 10$ (Fig. $1 A, B$ ) or an antibody recognizing the $\mathrm{A} \beta \mathrm{N}$ terminus (82E1; Fig. $1 C$ ), reveals expression of full-length APP as well as various proteolytic cleavage products, including $\mathrm{A} \beta$ (Fig. $1 B, C$ ), in transgenic mice. Immunohistochemistry for human APP reveals expression in neurons throughout the brain, including visual cortex (Fig. $1 D$; data not shown). These data provide evidence that human APP and $\mathrm{A} \beta$ can be detected in the brains of $A P P / P S 1$ mice as early as the critical period.

\section{Normal pattern of Arc expression upon light stimulation in APP/PS1 mice}

We next assessed the response of neurons in visual cortex of transgenic and nontransgenic mice to visual stimulation. Induction of the immediate early gene Arc was performed on P33 APP/ PS1 and nontransgenic mice (Fig. 2A-D,G). The method of Arc induction provides a convenient readout of the distribution of neurons functionally connected to the stimulated eye (Tagawa et al., 2005). As expected, Arc mRNA is induced in many neurons throughout V1 contralateral to the stimulated eye (Fig. 2A,C), with a small domain located within the binocular region of $\mathrm{V} 1$ responding in ipsilateral cortex (Fig. $2 B, D$ ). The pattern and width of induction is identical in nontransgenic and APP/PS1 mice (width of domain of layer $2 / 3$ cells in visual cortex respond-

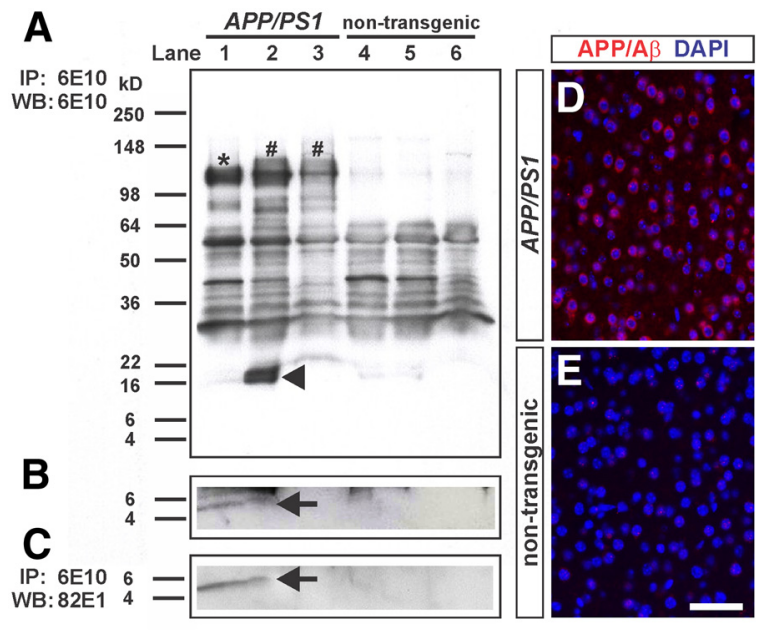

Figure 1. Expression of APP and $A \beta$ in critical period-age APP/PS1 mice. $\boldsymbol{A}-\boldsymbol{C}$, Fractionated brain homogenates from a P28 APP/PS1 mouse (lanes 1-3) and a nontransgenic litter mate (lanes 4-6). Brain homogenates were sequentially fractionated in TBS (lanes 1 and 4), 1\% Triton X-100 (lanes 2 and 5), and 2\% SDS (lanes 3 and 6). Immunoprecipitation with human APP/A $\beta$ antibody 6 E10 was performed with each fraction. Samples were run on a $10-20 \%$ SDS polyacrylamide gel, blotted, and probed with $6 \mathrm{E} 10(\boldsymbol{A}, \boldsymbol{B})$, then stripped and reprobed with anti-N-terminal A $\beta$ antibody 82 E1 (C). Secreted, $\alpha$ secretase-cleaved APP is present in lane 1 $(>98 \mathrm{kDa}$; labeled *). Membrane-bound, full-length human APP is present in lanes 2 and 3 (>98 kDa; labeled \#). Membrane-bound, BACE-cleaved, APP (termed C99; $16 \mathrm{kDa}$ band) is present in lane 2 (arrowhead). $A 4 \mathrm{kDa}$ band representing soluble, monomeric $A \beta$ is present in lane 1 upon longer exposure of blot to film (arrow; $\boldsymbol{B}$ ), and upon stripping and reprobing with $82 \mathrm{E} 1$ (arrow; $\boldsymbol{C}$. D, $\boldsymbol{E}$, Coronal sections of $\mathrm{P} 26$ cerebral cortex from transgenic $(\boldsymbol{D})$ or nontransgenic $(\boldsymbol{E})$ litter mates are immunostained for APP and $A \beta$ (6E10; red). Cortical layers 2- 4 are shown. Most cortical neurons express human APP. Nuclei are labeled with DAPI (blue). Scale bar, $50 \mu \mathrm{m}$.

ing to ipsilateral eye stimulation in nontransgenic mice, $907 \pm 13$ $\mu \mathrm{m}$; $A P P / P S 1$ mice, $902 \pm 15 \mu \mathrm{m} ; p>0.79$; nontransgenic layer 4, $1039 \pm 46 \mu \mathrm{m} ; A P P / P S 1$ layer 4, $1037 \pm 61 \mu \mathrm{m} ; p=0.90$; nontransgenic layer 5, $959 \pm 62 \mu \mathrm{m} ; A P P / P S 1$ layer 5, $984 \pm 59$ $\mu \mathrm{m} ; p=0.33$; nontransgenic layer $6,1050 \pm 56 \mu \mathrm{m} ; A P P / P S 1$ layer $6,1079 \pm 73 \mu \mathrm{m} ; p=0.30 ; n=10-13$ mice in each group; Fig. $2 B, D, G)$. These data indicate that the basic spatial extent and laminar distribution of the visual cortical response to light is similar in juvenile APP/PS1 and nontransgenic mice, and suggest that the underlying anatomy of the geniculocortical projection is not influenced by the presence of the transgenes or their products.

\section{Defect in ODP in APP-expressing transgenic mice}

To evaluate critical period ODP in APP/PS1 mice, unilateral eyelid suture was performed on P28 mice. Mice experienced MD for the subsequent $4 \mathrm{~d}$, followed by Arc induction via stimulation of the nondeprived eye. ODP was then assessed by measuring the change in width of $A r c$ mRNA induction in neurons located in layer $2 / 3$ of visual cortex. As expected, following $4 \mathrm{~d}$ of $\mathrm{MD}$, nontransgenic mice demonstrate an expansion in the domain of Arc mRNA induction relative to mice reared with normal binocular vision (Fig. $2 E, G$ ), indicative of normal OD plasticity related to the nondeprived eye (Tagawa et al., 2005). Strikingly, APP/PS1 mice fail to demonstrate any expansion following a $4 \mathrm{~d}$ period of $\operatorname{MD}(p>0.15, n=10$ in each group; Fig. $2 F, G)$.

Although APP/PS1 mice lack expected OD plasticity in response to a $4 \mathrm{~d}$ period of $\mathrm{MD}$ during the critical period, it remains possible that a stronger and longer period of monocular visual deprivation might elicit a response. Longer periods of depriva- 

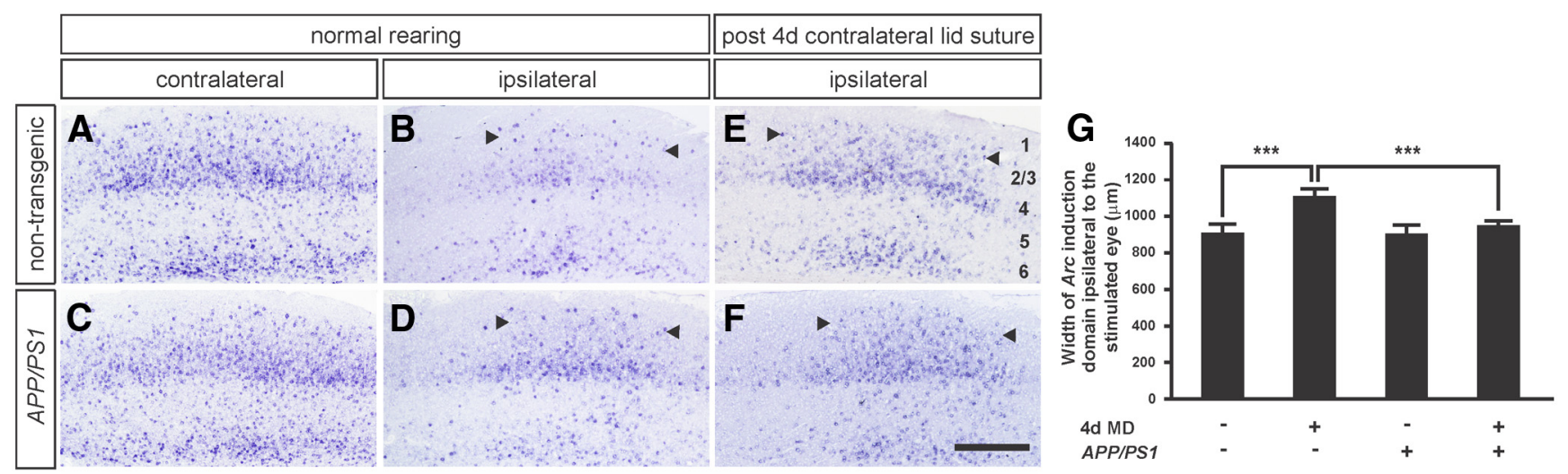

Figure 2. Ocular dominance plasticity defect in APP/PS1 mice following $4 \mathrm{~d}$ monocular visual deprivation. $\boldsymbol{A}-\boldsymbol{F}$, Coronal sections of visual cortex showing the pattern of Arc mRNA induction following stimulation of one eye. The laminar and areal pattern of induction is indistinguishable in nontransgenic $(\boldsymbol{A}, \boldsymbol{B})$ and $A P P / P S 1(C, D)$ mice in the absence of deprivation. Following a $4 \mathrm{~d}$ period of eye lid suture (P28 -P32), nontransgenic mice demonstrate a normal expansion in the width of visual cortex responsive to input driven by the ipsilateral, nondeprived eye (E), whereas APP/PS1 mice do not demonstrate this expansion $(\boldsymbol{F})$. A rrowheads denote medial and lateral edges of responding visual cortex ipsilateral to stimulated eye. The right edges of $\boldsymbol{A}$ and $\boldsymbol{C}$ are medial and the left edges of $\boldsymbol{B}$ and $\boldsymbol{D}-\boldsymbol{F}$ are medial. Cortical layers are labeled in $\boldsymbol{E}$. Scale bar, $400 \mu \mathrm{m}$. $\boldsymbol{G}$, Quantitation of the results demonstrated in $\boldsymbol{B}-\boldsymbol{F} . n=7-13$ mice per group. Error bars denote SD. ${ }^{* * *} p<$ $0.0001, t$ test.
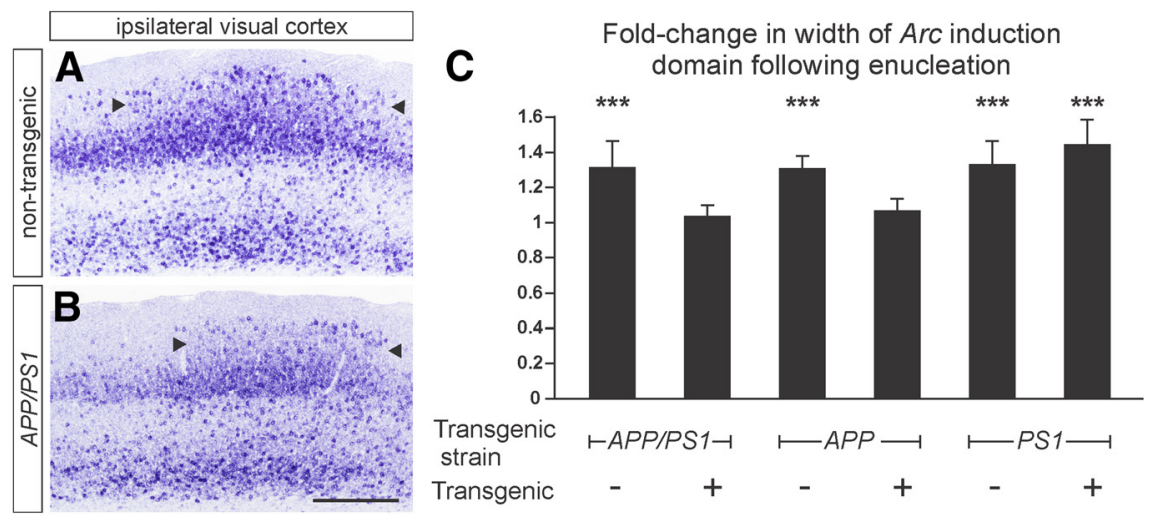

Figure 3. Critical period ODP defect in APP-expressing mice following a $10 \mathrm{~d}$ period (P22-P32) of ME. A,B, The expansion in the domain of Arc mRNA induction in visual cortex ipsilateral to the remaining, open eye in nontransgenic mice $(\boldsymbol{A})$ does not occur in APP/PS1 ( $B$ ) mice. Arrows denote medial and lateral limits of the domain of Arc-expressing layer $2 / 3$ neurons. Medial is to the left in each image. Scale bar, $400 \mu \mathrm{m}$. C, Fold-change in the width of the domain of Arc mRNA induction in visual cortex ipsilateral to the remaining, open eye following a $10 \mathrm{~d}$ period of $M E$ compared with normally reared nontransgenic litter mates and transgenic mice which express APPswe and PS1dE9 (APP/PS1), APPswe alone (APP), or PS1dE9 alone (PS1). $n=6-17$ mice per group. Error bars denote $S D .{ }^{* * *} p<0.0001, t$ test comparing width of Arc induction domain following $10 \mathrm{~d}$ ME to that of normally reared mice of the same genotype and age.

tion and also ME produce a stronger response in OD plasticity compared with a 4 d period of MD (Horton and Hocking, 1998; Tagawa et al., 2005). APP/PS1 and nontransgenic mice underwent ME at P22, followed by Arc induction via the intact eye at P33. In nontransgenic mice, within visual cortex ipsilateral to the nondeprived eye, there is a robust expansion of the domain driven by visual stimulation, as assessed by Arc mRNA induction in layer $2 / 3$ cells (Fig. $3 A, C$ ). The $10 \mathrm{~d}$ period of monocular vision elicited strong OD plasticity in this assay in nontransgenic mice, consistent with published results (Tagawa et al., 2005; Syken et al., 2006; Datwani et al., 2009). In contrast, no significant increase in the width of the domain of Arc induction was observed in APP/PS1 mice even following this prolonged period of $\mathrm{ME}(p>$ 0.81 ; Fig. $3 B, C$ ). Thus, these observations further illustrate the disruption of ODP in the transgenic mice.

OD plasticity was also examined in an independent transgenic line that overexpresses APPswe alone. Using the strong protocol of $10 \mathrm{~d} \mathrm{ME}$, no significant expansion of territory belonging to the open eye was detected $(n=10-16$ mice per group; Fig. $3 C$ ), implying that the absence of OD plasticity in these mice is not line-specific, nor is it dependent on the expression of mutant PS1. Consistent with this suggestion, transgenic mice that express mutant PS1 alone exhibit normal ODP, excluding the possibility that the defect in ODP observed in APP/PS1 mice is due to an APP-independent effect of mutant PS1 expression (Fig. 3C).

\section{Defect in ODP assessed by imaging in awake mice}

The results of the Arc induction experiments above demonstrate that following short or long periods of monocular deprivation, there is a defect in ODP as indicated by a failure of the functional representation of the nondeprived eye to expand within visual cortex. To confirm this result and to compare responses to stimulation of each eye before and after MD in individual animals, OD plasticity was next examined in vivo using wide-field imaging of intrinsic signals during localized visual stimulation. Optical intrinsic signal imaging is a well established method for assessing retinotopic organization, the relative strength of cortical responses to stimulation of ipsilateral and contralateral eyes, as well as changes in response strength that occur following MD (Grinvald et al., 1986; Schuett et al., 2002; Cang et al., 2005; Hofer et al., 2009; Tohmi et al., 2009). The measured intrinsic signal is thought to be a result of neuronal activity and hemodynamic responses, both of which may be reduced by anesthesia and the behavioral state of the animal (Berwick et al., 2002; Niell and Stryker, 2010), prompting us to perform our analysis in awake mice that were habituated to head fixation.

Mice were presented with drifting gratings positioned at one of three horizontal locations on an LCD monitor (each stimulus spanning $16^{\circ}$ of the visual field; see Materials and Methods), to assess retinotopic organization as well as to determine the coor- 
dinates of the binocular region of visual cortex that produced maximal responses to stimulation of the ipsilateral eye (Fig. $4 A-$ $C)$. To ensure that cortical responses to visual stimulation following cranial window installation were comparable in nontransgenic and APP/PS1 mice, cranial window installation was performed on P22-P24 and mice were allowed to recover from surgery for 5-6 d before imaging at P27-P29 (Fig. $4 A)$. No significant difference was observed comparing the magnitude of cortical responses to visual stimulation of ipsilateral or contralateral eye in APP/PS1 mice and nontransgenic mice ( $d F / F$ nontransgenic ipsilateral stimulation: $0.19 \pm 0.05 \% ; A P P / P S 1$ ipsilateral stimulation: $0.22 \pm 0.03 \%$; $\mathrm{p}=$ 0.661 ; nontransgenic contralateral eye stimulation: $0.39 \pm 0.05 \%$; APP/PS1 contralateral eye stimulation: $0.30 \pm 0.03 \% ; p=$ 0.112 ; $t$ test; $n=7-8$ per group; \pm SEM; Fig. $5 C)$, suggesting that transgene expression does not affect the overall responsiveness of the visual cortex following window placement. The magnitude of shifts in peak response location following a shift in visual stimulus location did not differ between nontransgenic and APP/PS1 mice (Fig. $4 D$; two-tailed rank sum test, $p>0.28$; see Materials and Methods), nor was there any difference in the spatial extent of responses to a localized $16^{\circ}$ stimulus (Fig. $4 E$; two-tailed rank sum test, $p>0.4)$. No significant differences ( $t$ tests, $p>0.05$ ) were observed at P28 between nontransgenic and APP/PS1 mice in retinotopic spacing (Fig. $4 D$ ), response width (Fig. 4E), ipsilateral eye response amplitude (Fig. 5C) or contralateral eye response amplitude (Fig. 5C), suggesting that $A P P / P S 1$ mice have grossly intact visual responses and cortical retinotopic organization.

Mice then underwent a $4 \mathrm{~d}$ period of $\mathrm{MD}$, after which imaging of responses to both deprived and nondeprived eye stimulation was again conducted (Fig. 5A). Nontransgenic mice demonstrate the expected, weakened response to stimulation of the deprived, contralateral eye (pre-MD, $0.39 \pm 0.05$; post-MD $0.21 \pm 0.04 ; p<0.01, t$ test; Fig. $5 B, C)$. Although the increase in the magnitude of responses to the ipsilateral, nondeprived eye is not statistically significant (pre-MD, $0.194 \pm 0.048$; post-MD, $0.222 \pm 0.028 ; p=0.1435$; Fig. $5 B, C$ ), there is a decrease in the ODI following MD (nontransgenic ODI pre-MD, $0.428 \pm 0.065$; nontransgenic ODI post-MD, $-0.027 \pm 0.100 ; p=0.005$; Fig. $5 D)$. Before $\mathrm{MD}, A P P / P S 1$ mice demonstrate a smaller ratio of contralateral to ipsilateral response strengths $(A P P / P S 1 \mathrm{C} / \mathrm{I}$ ratio, $1.49 \pm 0.21$; nontransgenic $\mathrm{C} / \mathrm{I}$ ratio, $2.58 \pm 0.43 ; p=0.035, t$ test; Fig. $5 C$, see Discussion). In addition, $A P P / P S 1$ mice demonstrate no significant change in ODI measurements following MD $(A P P / P S 1$ ODI pre-MD, $0.160 \pm 0.063 ; A P P / P S 1$ ODI post-MD, $0.333 \pm 0.084 ; A P P / P S 1$ ODI pre-MD vs post-MD, $p=0.28$; pre-MD ODI nontransgenic vs $A P P / P S 1, p=0.03$; post-MD ODI


(2 Hz, .03 cpd)

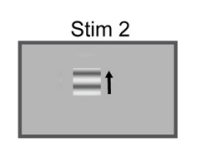

Stim 3

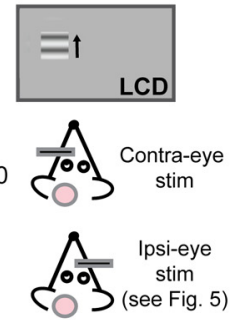

E
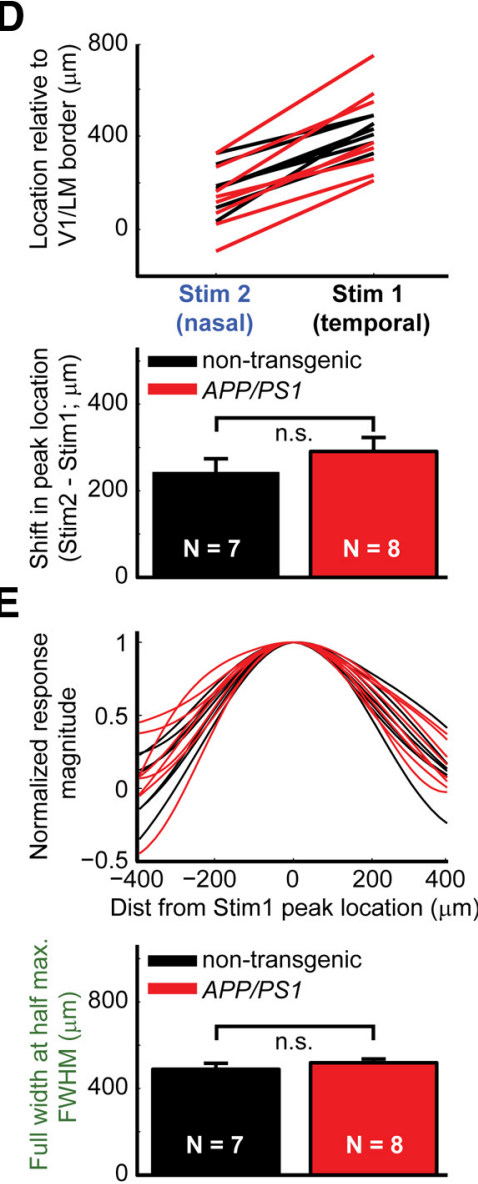

Figure 4. In vivo imaging indicates normal retinotopic acuity in awake APP/PS1 mice. $A$, Experimental timeline. Cranial window and headpost installation was performed on P22-P24, followed by optical imaging $5-6$ d later. $\boldsymbol{B}$, Visual responses in nontrans fluorescence, \% dF/F; see Materials and Methods). Dark regions indicate responses in areas V1, LM, and AL (anterolateral). A strip along the V1/LM axis was constructed, and smoothed maximum responses along this strip were used to 列 (dashed blue vertical lines). D, Retinotopic progression of peak responses from Stim 2 to Stim1 location. Top, Peak (two-tailed rank sum test, $p>0.28$ ). $\boldsymbol{E}$, Top, Normalized response cross-sections (Stim1), centered at peak response. Bottom, Average estimates of full-width at half-maximum (see green arrow in C) did not differ significantly between nontransgenic and APP/PS1 mice (two-tailed rank sum test, $p>0.4$ ).

nontransgenic vs $A P P / P S 1, p=0.04$; Fig. $5 D)$. Following $\mathrm{MD}$ in $A P P / P S 1$ mice, responses to stimulation of the deprived, contralateral eye decrease in magnitude (pre-MD, $0.30 \pm 0.03$; post-MD, $0.19 \pm 0.03 ; p=0.015$; Fig. $5 C$ ), suggesting that weakening of responses to the deprived eye is intact, however, the magnitude of responses to stimulation of the nondeprived eye also decrease (preMD, $0.22 \pm 0.03$; post-MD, $0.09 \pm 0.02 ; p=0.015$; Fig. $5 C$ ). In sum, the decrease in ODI present in nontransgenic mice does not occur in APP/PS1 mice following $4 \mathrm{~d} \mathrm{MD}$ (nontransgenic, $-0.455 \pm 0.109$; $A P P / P S 1,0.146 \pm 0.108, p=0.0057, t$ test), confirming that $A P P /$ PS1 mice have reduced ocular dominance plasticity (Fig. $5 D$ ).

In addition to this marked abnormality in plastic response to $4 \mathrm{~d} \mathrm{MD}, A P P / P S 1$ mice also appear to have a more subtle defect. As described above, we observe a decreased ratio of contralateral to ipsilateral response strengths even with normal rearing up to 

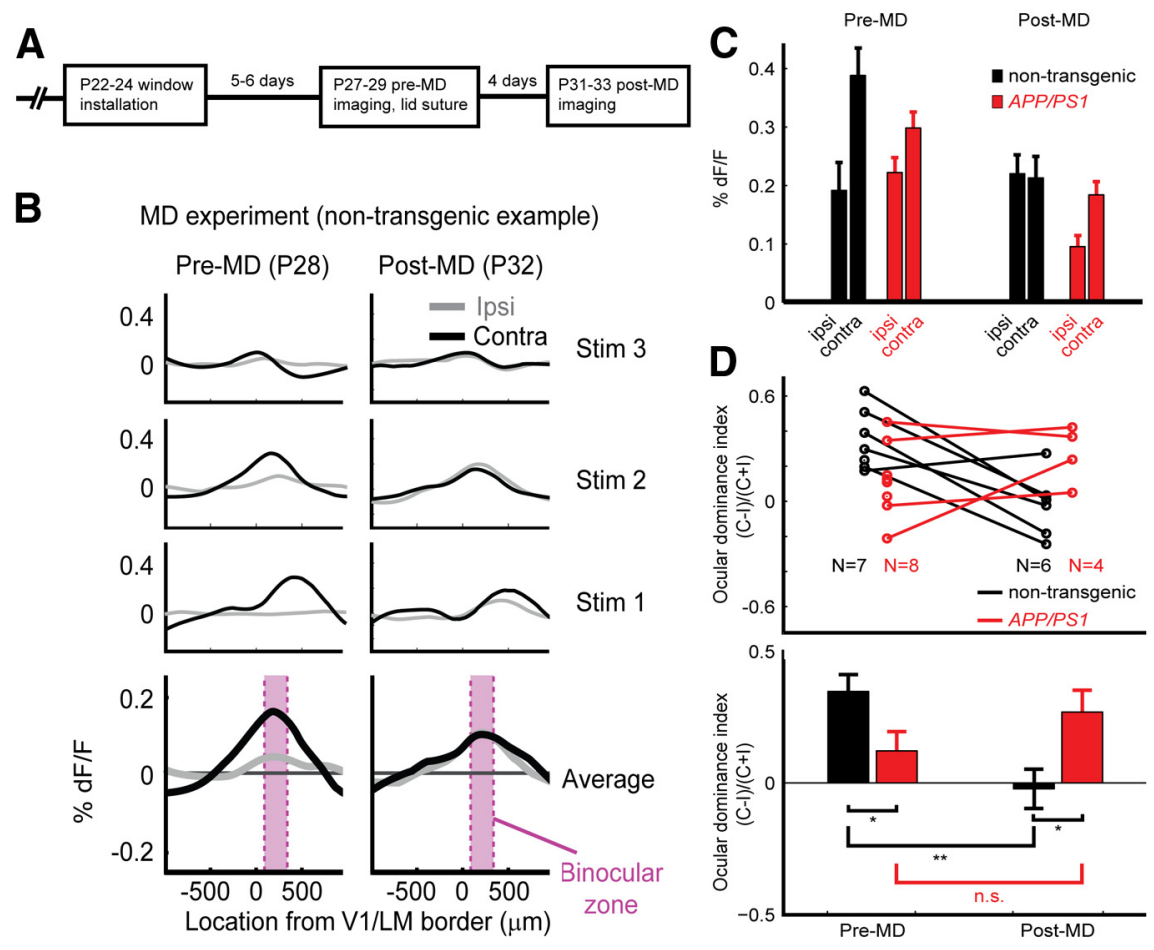

Figure 5. In vivo imaging indicates that OD plasticity is decreased in APP/PS1 mice. $A$, Experimental timeline. Following imaging at P27-P29, MD was performed, animals experienced MD for $4 d$, then the sutured eyes were reopened and mice were reimaged. $\boldsymbol{B}$, Example of OD plasticity following $4 \mathrm{~d}$ of MD in a nontransgenic mouse. Left, Spatial response profiles for deprived, contralateral eye (contra; black lines) and nondeprived, ipsilateral eye (ipsi; gray lines) stimulation at three retinotopic locations, and average response (bottom) across all stimulus locations. Right, Responses from the same region of cortex, following MD. C, Summary of binocular zone responses to ipsi and contra eye stimulation across nontransgenic (black) and APP/PS1 (red) mice pre- and post-MD. The average responses $100-350 \mu \mathrm{m}$ from the V1/LM border were used (violet rectangles in $\boldsymbol{B}$; see Materials and Methods). D, Top, Response bias to contra eye stimuli was computed as $0 \mathrm{DI}=($ contra - ipsi) $/($ contra + ipsi) for each experimental session. Indices from the same mouse pre-MD and post-MD are connected by a line. Bottom, Average ODI across all sessions. ODI values were significantly decreased by MD in nontransgenic mice $\left({ }^{* *} p<0.01\right)$ but not in APP/PS1 mice $(p=0.27)$. We also noted a significant decrease in ODI before MD, in APP/PS1 mice $\left({ }^{*} p<0.05\right)$. Error bars denote SEM.

P28. This change in the contralateral to ipsilateral eye ratio is reminiscent of the alteration recently described in dark-reared mice (McCurry et al., 2010), suggesting that APPswe/A $\beta$ expression may subtly interfere with activity-dependent establishment of normal contralateral to ipsilateral eye binocularity even in the absence of monocular deprivation.

\section{Discussion}

We tested the hypothesis that overexpression of APP disrupts fundamental mechanisms of synaptic plasticity in the intact nervous system. The major finding of this study is that dramatic deficits in synaptic plasticity can be detected in the cerebral cortex of APPswe-expressing transgenic mice in vivo. We demonstrate a defect in ocular dominance plasticity in the visual cortex during the peak of the critical period, i.e., in the fourth and fifth weeks of life. Following either a brief period of MD or an extended period of ME, the normal expansion of territory functionally connected to the open eye fails to occur in APPswe-expressing transgenic mice. This result, demonstrated using two complementary methods of assessing ODP, cannot be explained by a defect in the baseline functional organization of visual responses in APPsweexpressing mice or by an alteration in Arc transcription; APPswe-expressing transgenic mice reared with normal visual experience demonstrate a normal pattern of Arc induction and have similar visual retinotopic acuity as that of nontransgenic mice (Figs. $2 A-D, 4)$. The comparable width of the domain of visual cortex responsive to the ipsilateral eye in normally reared APPswe-expressing mice argues against a defect in maturation of visual system circuitry; previous studies using Arc induction in analyses of responses at earlier ages have shown that the domain of cortex responsive to ipsilateral eye stimulation is much wider at $\mathrm{P} 17$ and refines with maturation to the smaller size observed when testing animals at P28-P33 (Tagawa et al., 2005). The $\mathrm{C} / \mathrm{I}$ ratio in normally reared $A P P / P S 1$ mice is lower than that of nontransgenic mice, suggesting that there may be subtle developmental physiological changes that affect the establishment of normal binocular balance, however, there does not appear to be a serious maturational defect in APP-expressing transgenic mice. In addition, mice expressing APPswe alone (Tg2576; Hsiao et al., 1996) are known to perform normally on tasks that require visual function as late as 10 months of age, further suggesting that these mice do not have a defect in vision per se at 1 month of age.

A number of studies have looked at Arc expression in APP-expressing transgenic models and have demonstrated decreases (Wegenast-Braun et al., 2009), or increases (Grinevich et al., 2009; Perez-Cruz et al., 2011) in APP-expressing mice. We interpret these differences as the result of a number of variables that differ between each of the reported studies, including brain regions analyzed, strains and ages of mice studied, and behavioral assays performed. Our current analysis suggests that our readout of neuronal activity, Arc mRNA expression following a 30 min light exposure, is not affected by the expression of APP or A $\beta$ in APP-expressing mice at 1 month of age. It is also important to emphasize that, in contrast to the above studies, we examined induction of Arc expression in response to a specified visual stimulus.

The defect in ODP in visual cortex may be the earliest evidence of synaptic dysfunction in APPswe-expressing mice described to date. Transgenic mice are typically tested at much later ages and in some studies, cognitive deficits are not detected until mice begin to accumulate amyloid plaques (Hsiao et al., 1996; Chen et al., 2000; Billings et al., 2005). Memory deficits have been demonstrated before plaque formation in 3-month-old mice, but these defects were not detected at 2 months of age (D'Amelio et al., 2011). Our data suggest that even though synaptic dysfunction may be present at much earlier ages, compensation and functional redundancy at synapses or circuits responsible for learned behaviors may mask the basic synaptic dysfunction produced by constitutive expression of APP and A $\beta$. However, as we show here, this defect in synaptic plasticity can be revealed by an acute challenge in the form of MD or ME.

Our data suggest that APP-expressing transgenic mice are unable to generate a normal neocortical plastic response to the loss of input from one eye. In WT mice, studies have shown that OD plasticity in response to MD occurs in 2 phases (Frenkel and Bear, 2004; Kaneko et al., 2008; Smith et al., 2009). First there is a 
weakening of the cortical response to the deprived eye, followed later by strengthening of responses driven by stimulation of the nondeprived eye. The defect observed here in APP-expressing transgenic mice following $\mathrm{MD}$ or $\mathrm{ME}$ involves a failure of the nondeprived eye to expand its territory within visual cortex, as well as a defect in the mechanism of open-eye strengthening. The expansion of the responding domain to stimulation of the ipsilateral, nondeprived eye, following a $4 \mathrm{~d}$ period of $\mathrm{MD}$, was observed in nontransgenic mice, but not in APP-expressing mice, using $\operatorname{Arc}$ induction, a technique that captures the cortical response- at cellular resolution - to the complex visual stimulation presented to the mouse by allowing it to move freely within its home cage while exposed to light for $30 \mathrm{~min}$. Strengthening of responses to the nondeprived eye was not observed in nontransgenic mice in our optical imaging experiments, or those of others (McCurry et al., 2010). With lower spatial resolution, optical imaging provides a way of assessing the relative magnitude of responses using a stimulus much less likely to stimulate the cortex to the same degree as the stimulus provided in Arc induction. A larger proportion of the cells would have to respond to produce a measurable change by intrinsic imaging, which may be more evident following longer periods of MD (Kaneko et al., 2008; Tohmi et al., 2009). Our imaging analysis was restricted to responses to stimuli positioned $0-30^{\circ}$ from the vertical meridian, focusing our analysis on neuronal populations most likely to exhibit a plastic response following MD (Gordon and Stryker, 1996). Using optical imaging, we see abnormally weakened responses to the nondeprived eye following a $4 \mathrm{~d}$ period of MD in APP/PS1 mice, confirming an abnormality in the plastic response to the nondeprived eye. It is worth noting that mice lacking TNF $\alpha$ or TNF receptors have a similar OD plasticity defect, with deprived eye weakening remaining intact in these mutant mice, consistent with the proposal that weakening and strengthening involve distinct cellular and molecular mechanisms (Kaneko et al., 2008). Our observations raise the possibility that APPswe/A $\beta$ expression may alter the same mechanisms of synapse strengthening. Loss of function studies suggest that APP plays a role in neurite pruning and neuromuscular junction development (Wang et al., 2005; Nikolaev et al., 2009; Wang et al., 2009). In addition, $A \beta$ exposure has been shown to affect NMDA receptor function and calcineurin-dependent calcium signaling pathways (Hsieh et al., 2006; Shankar et al., 2007; Wu et al., 2010) crucial for intact ocular dominance plasticity during the critical period (Sawtell et al., 2003; Yang et al., 2005). We postulate that dysregulation of NMDA receptor activity or calcineurin signaling may play a role in the ODP defect in APPswe-expressing mice.

The current data suggest that overexpression of APPswe, and by implication, $\mathrm{A} \beta$, can have a marked effect on synaptic plasticity in the intact brain. Amyloid plaques exert complex effects on their local microenvironment, including increased glial activity, oxidative stress, disruption of calcium homeostasis, morphologic changes in dendrites and axons and alterations in activitydependent mRNA translocation and translation (Spires et al., 2005; Kuchibhotla et al., 2008; Meyer-Luehmann et al., 2009). By contrast, the current model system of OD plasticity reveals dramatic effects of $A \beta$ in a well studied form of systems-level synaptic plasticity in the absence of plaques (Garcia-Alloza et al., 2006), thus affording an opportunity to identify some of the physiologic changes that occur at the earliest stages of the disease process (Caselli et al., 2009). In addition to having potential relevance to Down syndrome developmental abnormalities, we speculate that these data support a role for $\mathrm{A} \beta$ accumulation in causing diminished plasticity responses consequent to lesion in the adult; if so, synaptic reserve may be increasingly compromised as the disease progresses and decrease patients' ability to withstand accumulating CNS insults. The robust nature of the ODP experimental paradigm represents a useful approach to understanding synaptic dysfunction and provides a way to test the efficacy of therapeutic agents in stopping or reversing the very early effects of $A \beta$ on synaptic function.

\section{References}

Abramov E, Dolev I, Fogel H, Ciccotosto GD, Ruff E, Slutsky I (2009) Amyloid-beta as a positive endogenous regulator of release probability at hippocampal synapses. Nat Neurosci 12:1567-1576.

Andermann ML, Kerlin AM, Reid RC (2010) Chronic cellular imaging of mouse visual cortex during operant behavior and passive viewing. Front Cell Neurosci 4:3.

Bentahir M, Nyabi O, Verhamme J, Tolia A, Horré K, Wiltfang J, Esselmann H, De Strooper B (2006) Presenilin clinical mutations can affect gammasecretase activity by different mechanisms. J Neurochem 96:732-742.

Berwick J, Martin C, Martindale J, Jones M, Johnston D, Zheng Y, Redgrave P, Mayhew J (2002) Hemodynamic response in the unanesthetized rat: intrinsic optical imaging and spectroscopy of the barrel cortex. J Cereb Blood Flow Metab 22:670-679.

Billings LM, Oddo S, Green KN, McGaugh JL, LaFerla FM (2005) Intraneuronal Abeta causes the onset of early Alzheimer's disease-related cognitive deficits in transgenic mice. Neuron 45:675-688.

Cang J, Kalatsky VA, Löwel S, Stryker MP (2005) Optical imaging of the intrinsic signal as a measure of cortical plasticity in the mouse. Vis Neurosci 22:685-691.

Caselli RJ, Dueck AC, Osborne D, Sabbagh MN, Connor DJ, Ahern GL, Baxter LC, Rapcsak SZ, Shi J, Woodruff BK, Locke DE, Snyder CH, Alexander GE, Rademakers R, Reiman EM (2009) Longitudinal modeling of age-related memory decline and the APOE epsilon4 effect. N Engl J Med 361:255-263.

Chen G, Chen KS, Knox J, Inglis J, Bernard A, Martin SJ, Justice A, McConlogue L, Games D, Freedman SB, Morris RG (2000) A learning deficit related to age and beta-amyloid plaques in a mouse model of Alzheimer's disease. Nature 408:975-979.

Chen QS, Wei WZ, Shimahara T, Xie CW (2002) Alzheimer amyloid betapeptide inhibits the late phase of long-term potentiation through calcineurin-dependent mechanisms in the hippocampal dentate gyrus. Neurobiol Learn Mem 77:354-371.

D’Amelio M, Cavallucci V, Middei S, Marchetti C, Pacioni S, Ferri A, Diamantini A, De Zio D, Carrara P, Battistini L, Moreno S, Bacci A, Ammassari-Teule M, Marie H, Cecconi F (2011) Caspase-3 triggers early synaptic dysfunction in a mouse model of Alzheimer's disease. Nat Neurosci 14:69-76.

Datwani A, McConnell MJ, Kanold PO, Micheva KD, Busse B, Shamloo M, Smith SJ, Shatz CJ (2009) Classical MHCI molecules regulate retinogeniculate refinement and limit ocular dominance plasticity. Neuron 64:463-470.

Fischer QS, Graves A, Evans S, Lickey ME, Pham TA (2007) Monocular deprivation in adult mice alters visual acuity and single-unit activity. Learn Mem 14:277-286.

Frenkel MY, Bear MF (2004) How monocular deprivation shifts ocular dominance in visual cortex of young mice. Neuron 44:917-923.

Garcia-Alloza M, Robbins EM, Zhang-Nunes SX, Purcell SM, Betensky RA, Raju S, Prada C, Greenberg SM, Bacskai BJ, Frosch MP (2006) Characterization of amyloid deposition in the APPswe/PS1dE9 mouse model of Alzheimer disease. Neurobiol Dis 24:516-524.

Goate A, Chartier-Harlin MC, Mullan M, Brown J, Crawford F, Fidani L, Giuffra L, Haynes A, Irving N, James L, et al. (1991) Segregation of a missense mutation in the amyloid precursor protein gene with familial Alzheimer's disease. Nature 349:704-706.

Gordon JA, Stryker MP (1996) Experience-dependent plasticity of binocular responses in the primary visual cortex of the mouse. J Neurosci 16:3274-3286.

Grinevich V, Kolleker A, Eliava M, Takada N, Takuma H, Fukazawa Y, Shigemoto R, Kuhl D, Waters J, Seeburg PH, Osten P (2009) Fluorescent Arc/Arg3.1 indicator mice: a versatile tool to study brain activity changes in vitro and in vivo. J Neurosci Methods 184:25-36.

Grinvald A, Lieke E, Frostig RD, Gilbert CD, Wiesel TN (1986) Functional 
architecture of cortex revealed by optical imaging of intrinsic signals. Nature 324:361-364.

Hofer SB, Mrsic-Flogel TD, Bonhoeffer T, Hübener M (2009) Experience leaves a lasting structural trace in cortical circuits. Nature 457:313-317.

Horton JC, Hocking DR (1998) Effect of early monocular enucleation upon ocular dominance columns and cytochrome oxidase activity in monkey and human visual cortex. Vis Neurosci 15:289-303.

Hsia AY, Masliah E, McConlogue L, Yu GQ, Tatsuno G, Hu K, Kholodenko D, Malenka RC, Nicoll RA, Mucke L (1999) Plaque-independent disruption of neural circuits in Alzheimer's disease mouse models. Proc Natl Acad Sci U S A 96:3228-3233.

Hsiao K, Chapman P, Nilsen S, Eckman C, Harigaya Y, Younkin S, Yang F, Cole G (1996) Correlative memory deficits, Abeta elevation, and amyloid plaques in transgenic mice. Science 274:99-102.

Hsieh H, Boehm J, Sato C, Iwatsubo T, Tomita T, Sisodia S, Malinow R (2006) AMPAR removal underlies Abeta-induced synaptic depression and dendritic spine loss. Neuron 52:831-843.

Husson TR, Mallik AK, Zhang JX, Issa NP (2007) Functional imaging of primary visual cortex using flavoprotein autofluorescence. J Neurosci $27: 8665-8675$.

Jankowsky JL, Slunt HH, Ratovitski T, Jenkins NA, Copeland NG, Borchelt DR (2001) Co-expression of multiple transgenes in mouse CNS: a comparison of strategies. Biomol Eng 17:157-165.

Kaneko M, Stellwagen D, Malenka RC, Stryker MP (2008) Tumor necrosis factor-alpha mediates one component of competitive, experiencedependent plasticity in developing visual cortex. Neuron 58:673-680.

Kim JH, Anwyl R, Suh YH, Djamgoz MB, Rowan MJ (2001) Use-dependent effects of amyloidogenic fragments of (beta)-amyloid precursor protein on synaptic plasticity in rat hippocampus in vivo. J Neurosci 21:1327-1333.

Kuchibhotla KV, Goldman ST, Lattarulo CR, Wu HY, Hyman BT, Bacskai BJ (2008) Abeta plaques lead to aberrant regulation of calcium homeostasis in vivo resulting in structural and functional disruption of neuronal networks. Neuron 59:214-225.

Kumar-Singh S, Theuns J, Van Broeck B, Pirici D, Vennekens K, Corsmit E, Cruts M, Dermaut B, Wang R, Van Broeckhoven C (2006) Mean ageof-onset of familial Alzheimer disease caused by presenilin mutations correlates with both increased Abeta42 and decreased Abeta40. Hum Mutat 27:686-695.

Lambert MP, Barlow AK, Chromy BA, Edwards C, Freed R, Liosatos M, Morgan TE, Rozovsky I, Trommer B, Viola KL, Wals P, Zhang C, Finch CE, Krafft GA, Klein WL (1998) Diffusible, nonfibrillar ligands derived from Abeta1-42 are potent central nervous system neurotoxins. Proc Natl Acad Sci U S A 95:6448-6453.

McCurry CL, Shepherd JD, Tropea D, Wang KH, Bear MF, Sur M (2010) Loss of Arc renders the visual cortex impervious to the effects of sensory experience or deprivation. Nat Neurosci 13:450-457.

Meyer-Luehmann M, Mielke M, Spires-Jones TL, Stoothoff W, Jones P, Bacskai BJ, Hyman BT (2009) A reporter of local dendritic translocation shows plaque-related loss of neural system function in APP-transgenic mice. J Neurosci 29:12636-12640.

Niell CM, Stryker MP (2010) Modulation of visual responses by behavioral state in mouse visual cortex. Neuron 65:472-479.

Nikolaev A, McLaughlin T, O’Leary DD, Tessier-Lavigne M (2009) APP binds DR6 to trigger axon pruning and neuron death via distinct caspases. Nature 457:981-989.

Nilsberth C, Westlind-Danielsson A, Eckman CB, Condron MM, Axelman K, Forsell C, Stenh C, Luthman J, Teplow DB, Younkin SG, Näslund J, Lannfelt L (2001) The 'Arctic' APP mutation (E693G) causes Alzheimer's disease by enhanced Abeta protofibril formation. Nat Neurosci 4:887-893.

Perez-Cruz C, Nolte MW, van Gaalen MM, Rustay NR, Termont A, Tanghe A, Kirchhoff F, Ebert U (2011) Reduced spine density in specific regions of CA1 pyramidal neurons in two transgenic mouse models of Alzheimer's disease. J Neurosci 31:3926-3934.

Prasher VP, Farrer MJ, Kessling AM, Fisher EM, West RJ, Barber PC, Butler AC (1998) Molecular mapping of Alzheimer-type dementia in Down's syndrome. Ann Neurol 43:380-383.

Rovelet-Lecrux A, Hannequin D, Raux G, Le Meur N, Laquerrière A, Vital A, Dumanchin C, Feuillette S, Brice A, Vercelletto M, Dubas F, Frebourg T, Campion D (2006) APP locus duplication causes autosomal dominant early-onset Alzheimer disease with cerebral amyloid angiopathy. Nat Genet 38:24-26.
Sato M, Stryker MP (2008) Distinctive features of adult ocular dominance plasticity. J Neurosci 28:10278-10286.

Savonenko A, Xu GM, Melnikova T, Morton JL, Gonzales V, Wong MP, Price DL, Tang F, Markowska AL, Borchelt DR (2005) Episodic-like memory deficits in the APPswe/PS1dE9 mouse model of Alzheimer's disease: relationships to beta-amyloid deposition and neurotransmitter abnormalities. Neurobiol Dis 18:602-617.

Sawtell NB, Frenkel MY, Philpot BD, Nakazawa K, Tonegawa S, Bear MF (2003) NMDA receptor-dependent ocular dominance plasticity in adult visual cortex. Neuron 38:977-985.

Schaeren-Wiemers N, Gerfin-Moser A (1993) A single protocol to detect transcripts of various types and expression levels in neural tissue and cultured cells: in situ hybridization using digoxigenin-labelled cRNA probes. Histochemistry 100:431-440.

Schuett S, Bonhoeffer T, Hübener M (2002) Mapping retinotopic structure in mouse visual cortex with optical imaging. J Neurosci 22:6549-6559.

Shankar GM, Bloodgood BL, Townsend M, Walsh DM, Selkoe DJ, Sabatini BL (2007) Natural oligomers of the Alzheimer amyloid-beta protein induce reversible synapse loss by modulating an NMDA-type glutamate receptor-dependent signaling pathway. J Neurosci 27:2866-2875.

Shankar GM, Li S, Mehta TH, Garcia-Munoz A, Shepardson NE, Smith I, Brett FM, Farrell MA, Rowan MJ, Lemere CA, Regan CM, Walsh DM, Sabatini BL, Selkoe DJ (2008) Amyloid-beta protein dimers isolated directly from Alzheimer's brains impair synaptic plasticity and memory. Nat Med 14:837-842.

Smith GB, Heynen AJ, Bear MF (2009) Bidirectional synaptic mechanisms of ocular dominance plasticity in visual cortex. Philos Trans R Soc Lond B Biol Sci 364:357-367.

Spires TL, Meyer-Luehmann M, Stern EA, McLean PJ, Skoch J, Nguyen PT, Bacskai BJ, Hyman BT (2005) Dendritic spine abnormalities in amyloid precursor protein transgenic mice demonstrated by gene transfer and intravital multiphoton microscopy. J Neurosci 25:7278-7287.

Syken J, Grandpre T, Kanold PO, Shatz CJ (2006) PirB restricts oculardominance plasticity in visual cortex. Science 313:1795-1800.

Tagawa Y, Kanold PO, Majdan M, Shatz CJ (2005) Multiple periods of functional ocular dominance plasticity in mouse visual cortex. Nat Neurosci 8:380-388.

Tanzi RE, Gusella JF, Watkins PC, Bruns GA, St George-Hyslop P, Van Keuren ML, Patterson D, Pagan S, Kurnit DM, Neve RL (1987) Amyloid beta protein gene: cDNA, mRNA distribution, and genetic linkage near the Alzheimer locus. Science 235:880-884.

Tohmi M, Takahashi K, Kubota Y, Hishida R, Shibuki K (2009) Transcranial flavoprotein fluorescence imaging of mouse cortical activity and plasticity. J Neurochem 109 [Suppl 1]:3-9.

Tropea D, Van Wart A, Sur M (2009) Molecular mechanisms of experiencedependent plasticity in visual cortex. Philos Trans R Soc Lond B Biol Sci 364:341-355.

Walsh DM, Klyubin I, Fadeeva JV, Cullen WK, Anwyl R, Wolfe MS, Rowan MJ, Selkoe DJ (2002) Naturally secreted oligomers of amyloid beta protein potently inhibit hippocampal long-term potentiation in vivo. Nature 416:535-539.

Wang P, Yang G, Mosier DR, Chang P, Zaidi T, Gong YD, Zhao NM, Dominguez B, Lee KF, Gan WB, Zheng H (2005) Defective neuromuscular synapses in mice lacking amyloid precursor protein (APP) and APP-Like protein 2. J Neurosci 25:1219-1225.

Wang Z, Wang B, Yang L, Guo Q, Aithmitti N, Songyang Z, Zheng H (2009) Presynaptic and postsynaptic interaction of the amyloid precursor protein promotes peripheral and central synaptogenesis. J Neurosci 29:10788-10801.

Wegenast-Braun BM, Fulgencio Maisch A, Eicke D, Radde R, Herzig MC, Staufenbiel M, Jucker M, Calhoun ME (2009) Independent effects of intra- and extracellular Abeta on learning-related gene expression. Am J Pathol 175:271-282.

Wu HY, Hudry E, Hashimoto T, Kuchibhotla K, Rozkalne A, Fan Z, SpiresJones T, Xie H, Arbel-Ornath M, Grosskreutz CL, Bacskai BJ, Hyman BT (2010) Amyloid \{beta\} induces the morphological neurodegenerative triad of spine loss, dendritic simplification, and neuritic dystrophies through calcineurin activation. J Neurosci 30:2636-2649.

Yang Y, Fischer QS, Zhang Y, Baumgärtel K, Mansuy IM, Daw NW (2005) Reversible blockade of experience-dependent plasticity by calcineurin in mouse visual cortex. Nat Neurosci 8:791-796. 